\title{
Programação em Python: Inserindo mulheres na tecnologia
}

\author{
Caroline Dantas ${ }^{1}$, Angélica Gouveia ${ }^{1}$, Mirtha L. Fernández Venero ${ }^{2}$ \\ ${ }^{1}$ Universidade Federal do ABC \\ ${ }^{2}$ Centro de Matemática, Computação e Cognição \\ Campus Santo André - Avenida dos Estados, 5001. 09210-580 \\ Bairro Santa Terezinha. Santo André - SP - Brazil. \\ \{caroline.dantas, angelica.gouveia\}@aluno.ufabc.edu.br, mirtha.lina@ufabc.edu.br
}

\begin{abstract}
This paper describes the experience of the Python Programming project: Inserting Women in Technology. The focus of the project was teaching programming for women using the Python programming language. The main goal of the project was to encourage the insertion of women in Information Technology and thus contribute to reduce the difference between the number of men and women in the area. The chosen language can be used in several areas such as web development, games, data mining and numeric and scientific calculations.
\end{abstract}

Resumo. Este artigo descreve a experiência do projeto Programação em Python: Inserindo Mulheres na Tecnologia. O foco do projeto foi o ensino de programação para mulheres usando a linguagem de programação Python. $O$ projeto teve como objetivo principal encorajar a inserção de mulheres na Tecnologia da Informação e desta forma contribuir para a diminuição da diferença entre o número de homens e mulheres na área. A linguagem escolhida pode ser utilizada em diversos âmbitos como desenvolvimento web, jogos, mineração de dados e cálculos numéricos e científicos.

\section{Introdução}

A Era da Informação tem como motor o desenvolvimento tecnológico que cresce dia após dia e dá o tom da sociedade atual. Mesmo com a crescente demanda de profissionais, o número de mulheres na área da tecnologia ainda é relativamente baixo. No entanto, a história do desenvolvimento tecnológico sempre foi marcada por grandes mulheres como Ada Lovelace, Katherine G. Johnson, Dorothy Vaughan, Mary Jackson, Betty Holberton, entre outras.

$\mathrm{Na}$ tentativa de tornar esse espaço mais democrático e igualitário, têm surgido iniciativas de Ensino de Programação voltadas para mulheres, com o objetivo de desmitificar que esse espaço é masculino. Uma dessas iniciativas é o Pyladies ${ }^{1}$, um grupo internacional que tem como objetivo prestar mentoria e assistência para mulheres ao redor do mundo. Outras iniciativas também se preocupam e empenham na inserção

\footnotetext{
${ }^{1}$ http://www.pyladies.com/
} 
de mulheres no mundo da tecnologia, como o Women TechMakers ${ }^{2}$, da Google e o Woman Up Games ${ }^{3}$, no mundo dos games. O MariaLab ${ }^{4}$ e Programaria ${ }^{5}$ são exemplos de iniciativas brasileiras de ensino de programação para mulheres.

Inspirado por essas iniciativas, e com posse de informações sobre a baixa participação de mulheres nesse campo na região do $\mathrm{ABC}$ paulista, foi criado o projeto de extensão Programação em Python: Inserindo mulheres na Tecnologia na Universidade Federal do ABC (UFABC). O público-alvo do projeto foram mulheres da comunidade acadêmica e a comunidade externa da UFABC; porém não se restringindo só a elas. As vagas foram disponibilizadas igualitariamente para os dois públicos.

O logo do projeto foi desenhado para apresentar a conjunção de dois elementos: o perfil de um rosto feminino e o símbolo da Linguagem Python como mostra a Figura 1. O primeiro faz alusão ao público-alvo do curso de extensão e para isso o perfil foi adornado de brincos. O segundo representa a transformação do cérebro após o domínio da linguagem Python, pois a forma de pensar e lidar com os problemas muda com o aprendizado dos conceitos de programação.

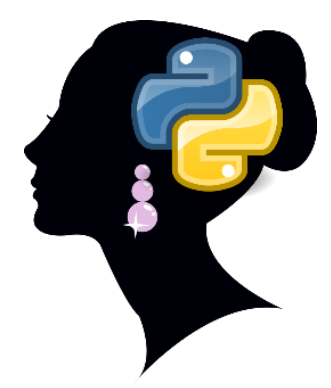

Figura 1: Logo do curso de extensão.

A ideia do projeto foi da estudante Caroline Dantas, aluna do Bacharelado de Ciência e Tecnologia (BCT) da UFABC. Ela resolveu propor um curso na universidade, de forma que houvesse inserção tanto das mulheres da comunidade acadêmica (alunas, docentes e técnicas administrativas), como da comunidade externa da região do $\mathrm{ABC}$ Paulista. Para isso a aluna Angélica Gouveia, também do BCT foi convidada para participar do projeto e definir algumas diretrizes, como a estrutura do curso e sua apresentação. Ambas, decidiram convidar uma professora que tivesse experiência nesse cenário, e que tivesse em mente também desmistificar as crenças errôneas sobre as dificuldades das mulheres na área da tecnologia e programação. Dessa forma, a professora Mirtha Lina Fernández Venero foi convidada para ser coordenadora do projeto de extensão, e auxiliar a dar vida ao ideal. Os esforços em equipe deram condições para a existência do projeto.

O presente artigo tem como objetivo descrever a experiência do projeto e está organizado como segue. A Seção 2 apresenta a fundamentação teórica usada ao longo

\footnotetext{
${ }^{2}$ https://www.womentechmakers.com/

${ }^{3}$ http://www.womenupgames.com/

${ }^{4}$ https://marialab.org/

${ }^{5}$ https://www.programaria.org/
} 
VI Congresso Brasileiro de Informática na Educação (CBIE 2017)

Anais dos Workshops do VI Congresso Brasileiro de Informática na Educação (WCBIE 2017)

do projeto. A Seção 3 aborda a metodologia e o desenvolvimento enquanto a Seção 4 apresenta uma análise dos resultados. Algumas considerações finais sobre a experiência são discutidas na Seção 5 .

\section{Fundamentação: Aprendizagem Significativa}

O curso foi elaborado utilizando como fundamento central a teoria preconizada por David P. Ausubel, psicólogo educacional estadounidense, conhecida como Aprendizagem Significativa [Ausubel et al. 1978]. A aprendizagem significativa tem sido usada em múltiplos contextos como, por exemplo modelagem matemática [Borssoi and de Almeida 2004], astronomia [Darroz and dos Santos 2013], física [Monteiro et al. 2006], química [Guimarães 2009], economia [Suder and Casagrande 1999] e ciências [Tavares 2008]. Segundo Ausubel,

"A essência do processo de aprendizagem significativa é que as ideias simbolicamente expressas sejam relacionadas de maneira substantiva (não-literal) e não arbitrária ao que o aprendiz já sabe, ou seja, a algum aspecto de sua estrutura cognitiva especificamente relevante para a aprendizagem dessas ideias. Este aspecto especificamente relevante pode ser, por exemplo, uma imagem, um símbolo, um conceito, uma proposição, já significativo. " [Ausubel et al. 1978, p.41].

$\mathrm{O}$ aspecto especificamente relevante, segundo Ausubel, denomina-se subsunçor (derivada da palavra inglesa "subsumer"), ou seja, são conceitos preexistentes na estrutura cognitiva (representações das experiências sensoriais) do indivíduo. O processo de aprendizagem significativa, segundo Ausubel, é representado na Figura 2 adaptada de [Moreira, 1999, pág. 157]. O primeiro estágio está na instigação do indivíduo a uma nova informação ou conceito. A partir disso, no segundo estágio ocorre a assimilação pelo subsunçor, onde o novo estímulo ou informação é associado aos conceitos preexistentes de maneira a coexistir na estrutura cognitiva. Por fim, em um último estágio acontece a modificação do subsunçor e também a estrutura cognitiva. Ausubel também propôs o conceito de organizadores prévios, para permitir a inserção de materiais introdutórios a fim de manipular a estrutura cognitiva e facilitar a aprendizagem significativa [Moreira. 1999].

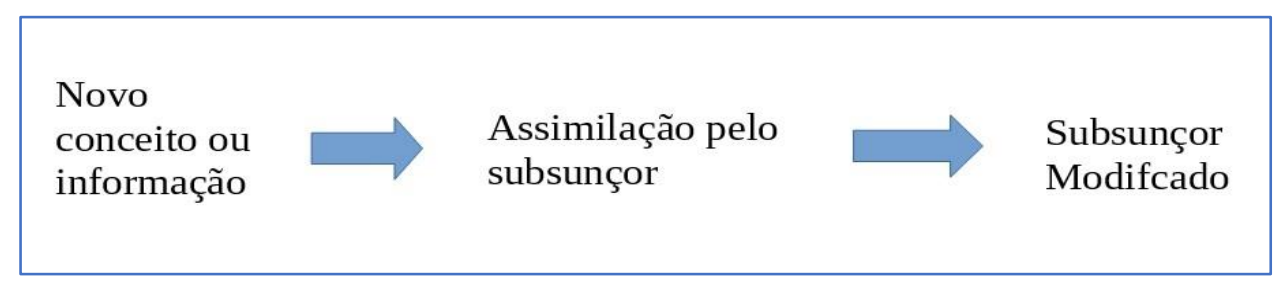

Figura 2: Representação sintética do processo de aprendizagem significativa.

A aprendizagem significativa destaca-se pelo seu aspecto de consideração ao conhecimento que o aluno já traz consigo, para que através dele sejam viabilizados novos conhecimentos. Por isso, ela foi usada para não restringir o público-alvo nem exigir pré-requisitos. Assim, nos slides das aulas preparados pelas instrutoras, foi levado em consideração dar destaque a situações corriqueiras que fossem de amplo conhecimento das alunas, tornando o aprendizado mais fluido. 
VI Congresso Brasileiro de Informática na Educação (CBIE 2017)

Anais dos Workshops do VI Congresso Brasileiro de Informática na Educação (WCBIE 2017)

\section{Metodologia e Desenvolvimento do Projeto}

O curso ocorreu do dia 06/07/2016 até o dia 07/12/2016, com aulas quinzenais de 3 horas, abordando o conteúdo dividido em 3 âmbitos:

1. Introdução histórica da linguagem Python, sua importância e uso, instalação e apresentação do IDE e a resolução de problemas usando algoritmos;

2. Os conceitos da linguagem Python;

3. Um projeto final individual envolvendo todos os conceitos estudados.

O curso teve uma grande demanda com 163 mulheres inscritas em dois dias (ver Figura 3). A procura foi de aproximadamente 5 vezes mais que o número de vagas que foram abertas, o que não era esperado pelas organizadoras dado o curto período de divulgação. A turma foi composta por 30 alunas sendo elas: 15 alunas do público interno da comunidade acadêmica da Universidade Federal do $\mathrm{ABC}$ e 15 alunas do público externo da comunidade do $\mathrm{ABC}$ e região.

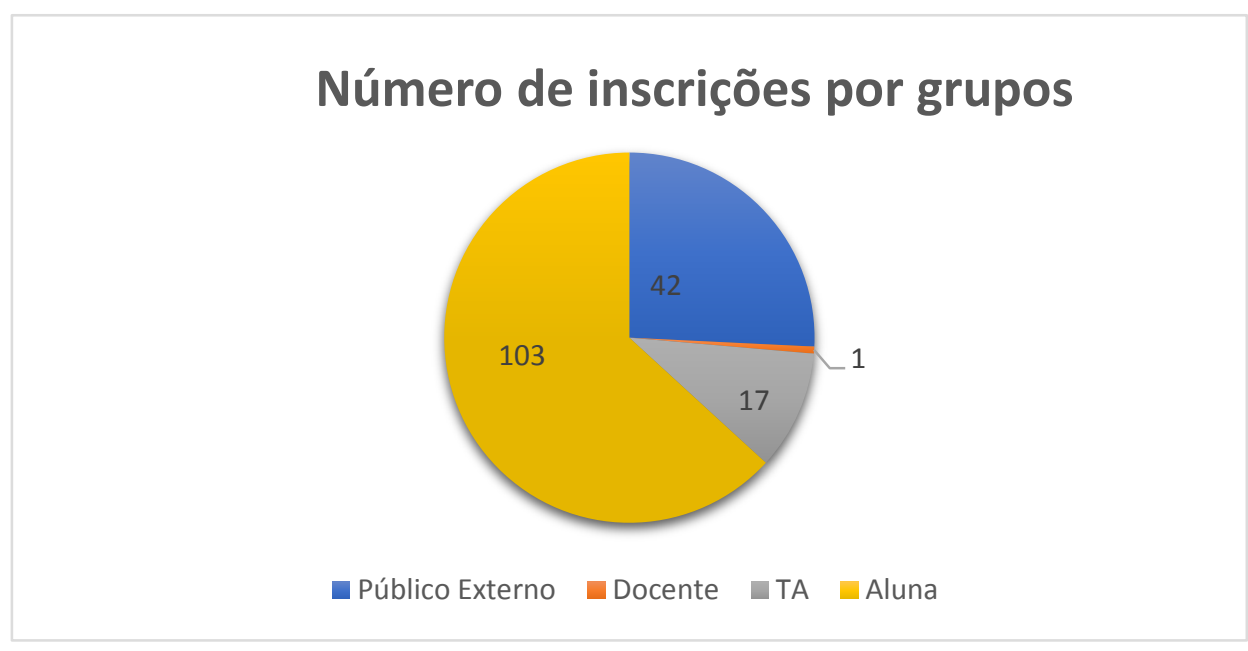

Figura 3: Número de inscritas divido por grupos.

Para a montagem das aulas foram utilizados três livros: [Menezes 2010] para cunho teórico e para os organizadores prévios; [Lutz and Ascher 2007] para complementação teórica e exercícios e [Borges 2014] para conceitos avançados. Cada aula foi dividida em três momentos: uma apresentação informal introdutória (organizadores prévios), fundamentação teórica e exercícios resolvidos e atividades práticas (exercícios para serem resolvidos no laboratório). $\mathrm{Na}$ abordagem dos organizadores prévios cada início de aula teve contextualização (tanto verbal quanto no material produzido) do tema com situações cotidianas aplicadas e de fácil associação aos conceitos posteriores. Após essa contextualização, foi apresentado o conteúdo teórico do tema de maneira a abordar um material didático, significativo, com exercícios resolvidos e potenciais aplicações nos mais diversos âmbitos. Todo o material usado foi produzido pelas instrutoras e, posteriormente a cada aula, disponibilizado numa pasta compartilhada no GDrive. A ferramenta de programação usada foi a versão 3.4 de Python em ambiente Linux. 
VI Congresso Brasileiro de Informática na Educação (CBIE 2017)

Anais dos Workshops do VI Congresso Brasileiro de Informática na Educação (WCBIE 2017)

O curso foi dividido em dois blocos como mostra a Figura 4, com um recesso de 15 dias entre eles. Antes do recesso foi feita uma aula de revisão na qual foram relembrados os tópicos referentes ao primeiro bloco. Também foram deixados exercícios propostos para a resolução em casa. No retorno, os exercícios foram resolvidos, e logo foi passado para o segundo bloco onde foram abordados os demais tópicos. Na última parte do curso foi desenvolvido um pequeno projeto guiado de programação, onde todos os tópicos vistos foram abordados.

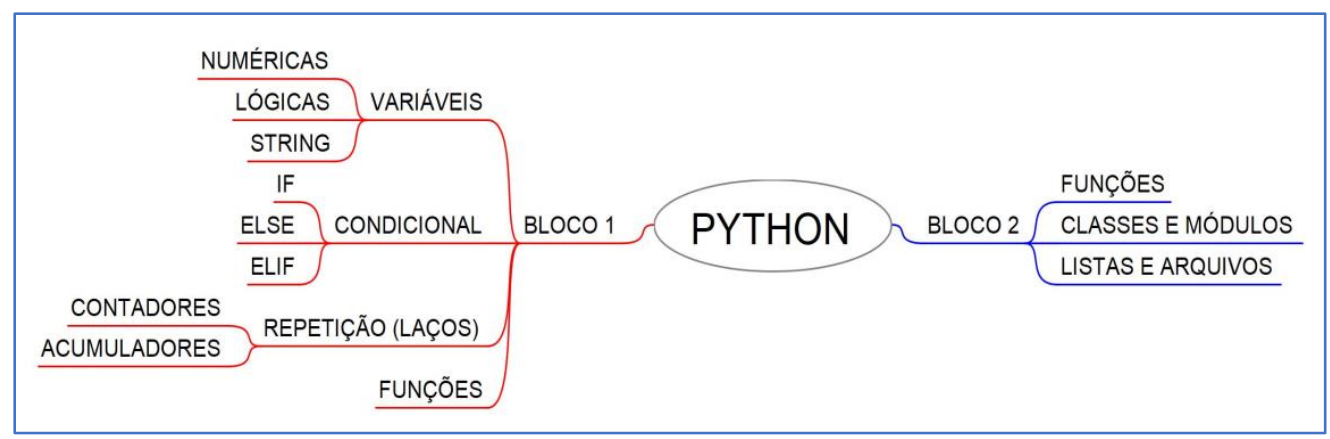

Figura 4: Tópicos estudados no curso.

As aulas foram inteiramente ministradas pelas estudantes, cada encontro lecionado por uma das instrutoras. Assim ambas tiveram a experiência de conduzir a sala, e também aprender conjuntamente com a turma. A ausência de professor na sala deu confiança tanto para as alunas quanto para as instrutoras.

Uma das primeiras dificuldades encontradas foi a seleção respeitando a ordem de inscrição. Para ter certeza que as meninas selecionadas estariam presentes no curso e evitar desistências posteriores, foi feita a confirmação com as meninas por e-mail. Outra dificuldade encontrada foi o tempo de recesso entre os quadrimestres da UFABC. A cada quadrimestre, o horário dos alunos muda; isso acabou criando o conflito entre as disciplinas da universidade e o horário do curso, o que levou às desistências. Porém a maior dificuldade foi o fato da turma ser bem desnivelada. No entanto, com trabalho em equipe foi possível contornar as dificuldades encontradas, principalmente para transmitir o conteúdo mais difícil, de maneira objetiva e clara.

\section{Análise dos Resultados}

O projeto teve 8 alunas concluintes, aproximadamente $27 \%$ das mulheres que começaram o curso, dentre elas cinco eram do público externo, duas alunas da UFABC e uma TA (ver Figura 5). Como se pode observar, a taxa de evasão foi muito grande, principalmente no grupo de alunas da UFABC. Em relação ao público externo, as principais causas foram relacionadas a problemas pessoais no decorrer do curso e também as dificuldades financeiras para o deslocamento até a UFABC. Logo podemos inferir que as principais causas dessa evasão foram:

1. As aulas aconteceram em dois quadrimestres. No segundo, a rotina das alunas mudou e ficou difícil conciliar os novos horários; 
VI Congresso Brasileiro de Informática na Educação (CBIE 2017)

Anais dos Workshops do VI Congresso Brasileiro de Informática na Educação (WCBIE 2017)

2. As diferenças de níveis dentro da mesma sala trouxeram consigo a necessidade de explicar tópicos básicos várias vezes e permanecer em outros mais avançados por mais tempo. Isto acabou sendo um dos motivos para que as alunas mais familiarizadas com a programação desistissem do curso;

3. As dificuldades pessoais.

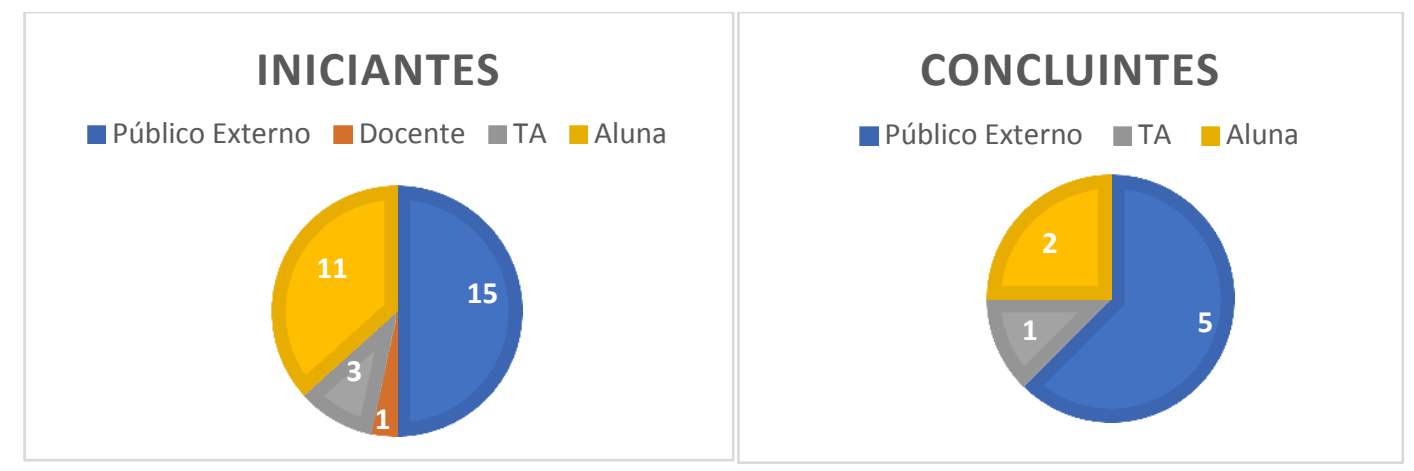

Figura 5: Comparativo entre iniciantes e concluintes do curso.

Mesmo diante desse quadro, podemos destacar que entre as concluintes, tivemos três mulheres na faixa dos 30 - 60 anos, e as outras cinco na faixa de 19 - 25. Com isso podemos observar o impacto em pessoas que dificilmente teriam contato com esse tipo de conteúdo fora do ambiente que foi por nós proposto. A desistência entre mulheres com a faixa etária de reinserção no mercado de trabalho ou que utilizam tecnologia em seu serviço, foi menor do que 5\%. Essas alunas mostraram maior engajamento no curso e manifestaram o desejo de usar o conhecimento aprendido para otimizar suas funções.

\section{Conclusões}

O curso mostrou que há uma grande demanda e interesse das mulheres por tecnologia, que buscam aprender e se desenvolver nessas áreas. Porém, o grau de conhecimento varia grandemente e, portanto, é necessário lidar primeiro com o nivelamento. Por isso, se o processo de seleção não garante o mesmo nível da turma, a estruturação do curso deve ser dividida em módulos básico, intermediário e avançado. Além disso, deve ser permitida a matrícula em cada módulo. Lidar com períodos contínuos e sem recesso é melhor para o processo de aprendizagem por não haver quebra de ritmo e rotina. A possibilidade de ajustar os horários do curso dependendo da composição da turma também pode ser um fator importante para evitar desistências.

Por ser um curso pensado por alunas para alunas, isso trouxe uma confiança mútua em ambos os lados e também foi possível criar um maior incentivo à cultura de ensino e aprendizagem contínua. A transmissão de conhecimento das instrutoras não veio só no âmbito da programação senão também das suas experiências como estudantes. Isso trouxe o encorajamento ao ensino para as participantes, ou seja, mostrar que é possível ensinar o que se sabe e isso ser de grande impacto aos que estão adquirindo esse conhecimento. $\mathrm{O}$ apoio da docente coordenadora foi de grande importância para que $\mathrm{o}$ curso fosse bem executado, tanto por lidar com as questões administrativas e apoio na metodologia. 
O curso mostrou que a inserção de mulheres na tecnologia é difícil. Há diversas variáveis que devem ser identificadas e trabalhadas para que as dificuldades sejam atenuadas. Essas experiências devem ser incentivadas não apenas no âmbito acadêmico, mas na sociedade como um todo. O número de inscrições evidenciou que não falta interesse das mulheres para atuar no campo da tecnologia, faltam espaços onde elas possam ser instigadas a participar, espaços inclusivos e afastados do preconceito de que certas áreas não são adequadas para o público feminino. Em geral, conforme o curso teve andamento tivemos diversos comentários positivos das alunas e ainda recebemos feedbacks relacionados à iniciativa. A maioria das alunas que desistiram em algum momento do curso continuaram seus estudos de forma independente. A experiência também foi de grande valia para as instrutoras, principalmente em aprender a revisar e transmitir seus conhecimentos, ter contato com alunas incríveis e ver as ideias de sonhos de cada uma delas que ainda servem de incentivo contínuo.

O projeto também demonstrou que, mesmo no contexto académico, é necessária a discussão da inserção das mulheres no mundo tecnológico. Quando o curso foi lançado, houve diversas reclamações e ataques à iniciativa por parte de alunos e técnicos da UFABC, por considerarem que o curso os deixavam à margem. Por isso, o curso de extensão de Programação em Python para iniciantes continua sendo ministrado por professores $^{6}$, sempre procurando conformar turmas com o mesmo número de alunas e alunos. Já o curso de Programação em Python para Mulheres, continua na UFABC como uma ação livre da aluna Caroline Dantas com mais duas turmas formadas.

\section{Referências}

Ausebel, D.P., Novak, J.D. and Hanesian (1978), H. Educational psychology: a cognitive view. $2^{\text {a }}$ edição. Nova York, Holt, Rinehart and Winston.

Borges, L.E. (2014) Python para Desenvolvedores. $1^{\text {a }}$ edição. Rio de Janeiro: Editora Novatec.

Darroz, L.M. and dos Santos, F.M.T. (2013) Astronomia: uma proposta para promover a aprendizagem significativa de conceitos básicos de Astronomia na formação de professores em nível médio. Caderno Brasileiro de Ensino de Física, Florianópolis, 30(1), $104-130$.

Guimarães, C. C. (2009). Experimentação no ensino de química: caminhos e descaminhos rumo à aprendizagem significativa. Química Nova na Escola, 31(3), 198-202.

Lutz M. and Ascher D. (2007) Aprendendo Python $2^{\circ}$ edição. Porto Alegre: Bookman Companhia Ed, 2007. 566 p.

Menezes, N.C. (2010) Introdução à programação com Python. $1^{a}$ edição. São Paulo: Editora Novatec.

Monteiro, B. D. S., Cruz, H. P., Andrade, M., Gouveia, T., Tavares, R., and dos Anjos, L. F. (2006). Metodologia de desenvolvimento de objetos de aprendizagem com foco na aprendizagem significativa. In Simpósio Brasileiro de Informática na Educação SBIE 1(1), 388-397.

\footnotetext{
${ }^{6}$ http://ufabc.space/CursoPython/
} 
VI Congresso Brasileiro de Informática na Educação (CBIE 2017)

Anais dos Workshops do VI Congresso Brasileiro de Informática na Educação (WCBIE 2017)

Moreira, M.A. (1999) Teorias de Aprendizagem. $1^{\text {a }}$ edição. São Paulo, EPU

Suder, C.E. and Casagrande, L.D.R. (1999) Aprendizagem significativa: relato de experiência no ensino superior. Paidéia (Ribeirão Preto) [online], 9 (17), 61-68.

Tavares, R. (2008). Aprendizagem significativa e o ensino de ciências. Ciências \& cognição, 13(1).

Borssoi, A.H. and de Almeida, L.M.W. (2004). Modelagem matemática e aprendizagem significativa: uma proposta para o estudo de equações diferencias ordinárias. Educação Matemática Pesquisa, 6(2). 